\title{
Influence of the Wash From Bronze on the Weathering of Marble
}

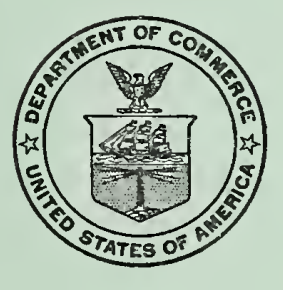

United States Department of Commerce

National Bureau of Standards

Building Materials and Structures Report 137 


\section{BUILDING MATERIALS AND STRUCTURES REPORTS}

On request, the Superintendent of Documents, U. S. Government Printing Office, Washington 25 , D. C., will place your name on a special mailing list to receive notices of new reports in this series as soon as they are issued. There will be no charge for receiving such notices.

If 100 copies or more of any reports are ordered at one time, a discount of 25 percent is allowed. Send all orders and remittances to the Superintendent of Documents, U. S. Government Printing Office, Washington $25, D$. C.

The following publications in this series are available by purchase from the Superintendent of Documents at the prices indicated:

BMS1 Research on Building Materials and Structures for Use in Low-Cost Housing -

BMS2

BMS3

BMS4

BMS5

BMS6

BMS7

BMS8

BMS9

Methods of Determining the Structural Properties of Low-Cost House Constructions.-

Suitability of Fiber Insulating Lath as a Plaster Base..

Accelerated Aging of Fiber Building Boards

Structural Properties of Six Masonry Wall Constructions.

Survey of Roofing Materials in the Southeastern States.

Water Permeability of Masonry Walls

Structural Properties of the Insulated Steel Construction Co.'s "Frameless-Steel" Con-

structions for Walls, Partitions, Floors, and Roofs
BMS10 Structural Properties of One of the "Keystone Beam Steel Floor" Constructions

Sponsored by the H. H. Robertson Co
BMS11 Structural Properties of the Curren Fabrihome Corporation's "Fabrihome" Construc-

tions for Walls and Partitions $\quad$ Structural Properties of "Steelox" Constructions for Walls, Partitions, Floors, and Roofs Sponsored by Steel Buildings, Inc

BMS13 Properties of Some Fiber Building Boards of Current Manufacture.-

BMS14 Indentation and Recovery of Low-Cost Floor Coverings-

BMS15 Structural Properties of "Wheeling Long-Span Steel Floor" Construction Sponsored

BMS16 Structural Properties of a "Tilecrete" Floor Construction Sponsored by Tilecrete Floors, Inc....

BMS17 Sound Insulation of Wall and Floor Constructions...

Supplement to BMS17, Sound Insulation of Wall and Floor Constructions

Supplement No. 2 to BMS17, Sound Insulation of Wall and Floor Constructions
BMS18 Structural Properties of "Pre-fab" Constructions for Walls, Partitions, and Floors Sponsored by the Harnischfeger Corporation

BMS19 Prcparation and Revision of Building Codes

BMS20 Structural Properties of "Twachtman" Constructions for Walls and Floors Sponsored by Connecticut Pre-Cast Buildings Corporation.

BMS21 Structural Properties of a Concrete-Block Cavity-Wall Construction Sponsored by the

National Concrete Masonry Association
BMS22 Structural Properties of "Dun-Ti-Stone" Wall Construction Sponsored by the W. E.

BMS23 Structural Properties of a Brick Cavity-Wall Construction Sponsored by the Brick Manufacturers Association of New York, Inc
uctural Properties of a Reinforced-Brick Wall Construction and a Brick-Tile

BMS24 Structural Properties of a Reinforced-Brick Wall Construction and a Brick-Tile

Cavity-Wall Construction Sponsored by the Structural Clay Products Institute--
BMS25 Structural Properties of Conventional Wood-Frame Constructions for Walls, Parti-

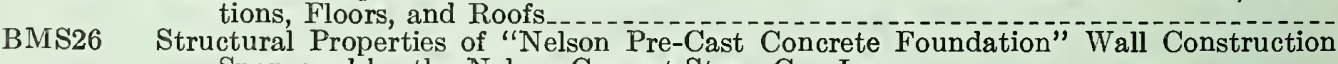
Sponsored by the Nelson Cement Stone Co., Inc

BMS27 Structural Properties of "Bender Steel Home" Wall Construction Sponsored by the Bender Body Co

BMS28 Backflow Prevention in Over-Rim Water Supplies

BMS29 Survey of Roofing Materials in the Northeastern States...

BMS30 Structural Properties of a Wood-Frame Wall Construction Sponsored by the Douglas Fir Plywood Association

BMS31 Structural Properties of "Insulite" Wall and "Insulite" Partition Constructions Sponsored by The Insulite Co...

"Out of print.

†Superseded by BMS116. 


\title{
Influence of the Wash From Bronze on the Weathering of Marble
}

\author{
Daniel W. Kessler and Ross E. Anderson
}

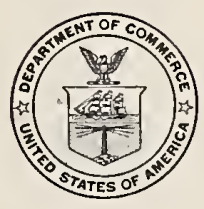

Building Materials and Structures Report 137

Issued 1953 JUN 231953

For sale by the Superintendent of Documents, U. S. Government Printing Office Washington 25, D. C. 


\section{Contents}

1. Introduction

1. Introduction $\ldots \ldots-1$

2. Outline of program

3. Description of materials

4. 'Tests on fresh marble

5. Description of exposure tests 3

6. Results of exposure tests

7. Observations on various marbles exposed to bronze

8. Discussion of results

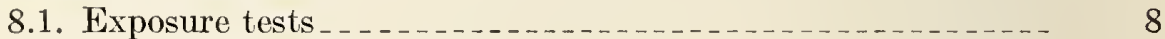

a. Untreated specimens _._.

b. Paraffin-treated specimens _... 8

c. Warping of marble $\ldots$

8.2. Observations on structures _..._. 8

8.3. Effect of infiltrating matter

9. Summary

10. References 


\title{
Influence of the Wash From Bronze on the Weathering of Marble
}

\author{
Daniel W. Kessler and Ross E. Anderson
}

\begin{abstract}
This investigation was made to determine whether rain water flowing over brouze work and then over marble in monuments or other structures causes deterioration of the marble. Experimental work included exposure tests, extending over a period of 131/2 years, in which many specimens of a white calcite marble were exposed to the wash from three bronzes of typical compositions. Tests for flexural strength, abrasive resistance, absorption, and bulk density were made on some of the specimens after exposure periods of 5,10 , and $13 \frac{1}{2}$ years to determine the changes in test values. Several buildings and monuments were inspected where various marbles had been exposed to the wash from bronze for periods ranging from 20 to 98 years.

It was found that some marbles are not appreciably injured by such conditions, whereas others showed advanced stages of disintegration within a period of 30 years. Some marbles develop both green and brown discelorations, and disintegration usually occurs in the brown areas. The green staining matter does not appear to have any appreciable affect on the durability of marble. Treatment of the marble with molten paraffin to seal the pores does not prevent discoloration except for a period of 2 or 3 years. Tests indicated that this treatment materially reduces the flexural strength and abrasive resistance of marble.
\end{abstract}

\section{Introduction}

The performance of marble in certain monuments, where it was used to support bronze castings, gave evidence that the wash from bronze is injurious to marble. Both green and brown discolorations appeared and deterioration of the marble occurred in the brown areas. Because there was no definite proof that the brown stains were caused by bronze, the deterioration could not be properly ascribed to this metal. Dark stains can be caused by other materials, either in the masonry or nearby.

Such structures are commonly erected without providing a means of diverting the wash from the bronze away from the marble, and stains often occur within a short time. Some valuable monuments, illustrated in figures 1 and 2, have shown appreciable deterioration within 20 years. Frequently, different blocks of marble from the same source show different degrees of resistance, as illustrated in figure 3.

Although there are various manifestations of weathering in marble and some of these appear more prominently on certain marbles than others, it will suffice for present purposes to consider only the more serious phase that gradually destroys the bond between grains. Often the first outward manifestation of this condition is a crack formation. The final stage, commonly called "sugaring", results when the bond between grains is so reduced that crumbling occurs. During the course of weathering the marble loses strength and increases in porosity and over-all dimensions. Some of the marbles are much more resistant to this kind of weathering than others, and the more resistant varieties may not show visible effects for many years, even though exposed to the most severe conditions.

About 15 years ago plans were made for a study at the Bureau to determine whether the brown stains on marble are caused by bronze and whether there is an accelerated weathering action in the discolored parts of the marble. It was hoped that such an investigation would add to the knowledge of weathering phenomena in masonry as well as to serve an economic purpose in pointing out the need of improved designs for such structures.

\section{Outline of Program}

It was decided to experiment with three typical bronze compositions on specimens of one representative marble. In order to accelerate the action, the bronzes were to be cut into fine shavings and exposed to the weather above the marble so that rain water would trickle down through the sharings and over the faces of the marble specimens. A sufficient number of specimens were to be used so that some could be removed and tested at the end of 5,10 , and 15 years of exposure. It was hoped that changes in test values for flexural strength, abrasive resistance, absorption, and bulk density during weathering would give satisfactory indications of the rates of deterioration as compared with control specimens exposed to the same weathering conditions but with no bronze in contact. 


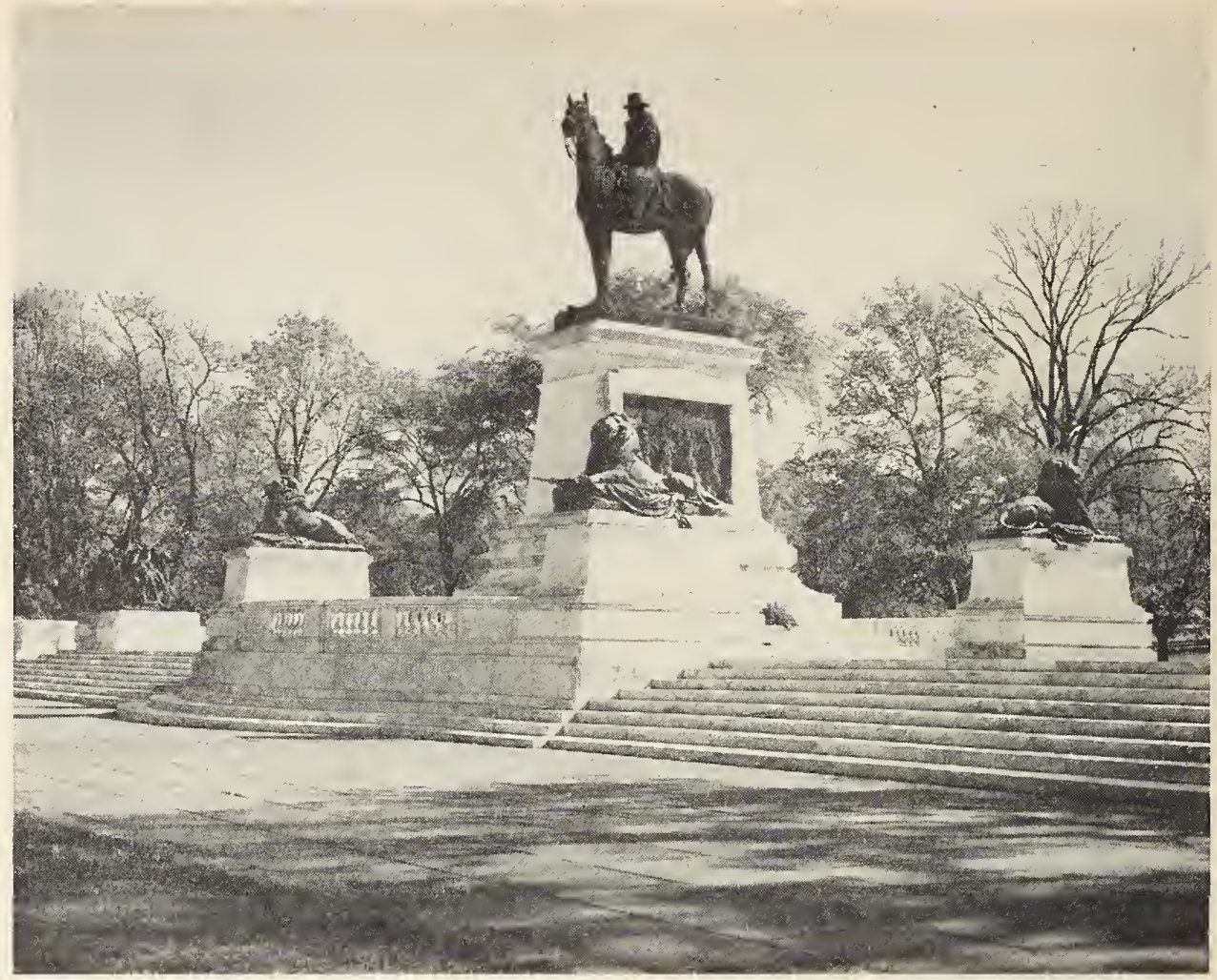

Figure 1. Grant Monument, Washington, D. C., from the southwest showing all but one of the bronze groups and the supporting marble.

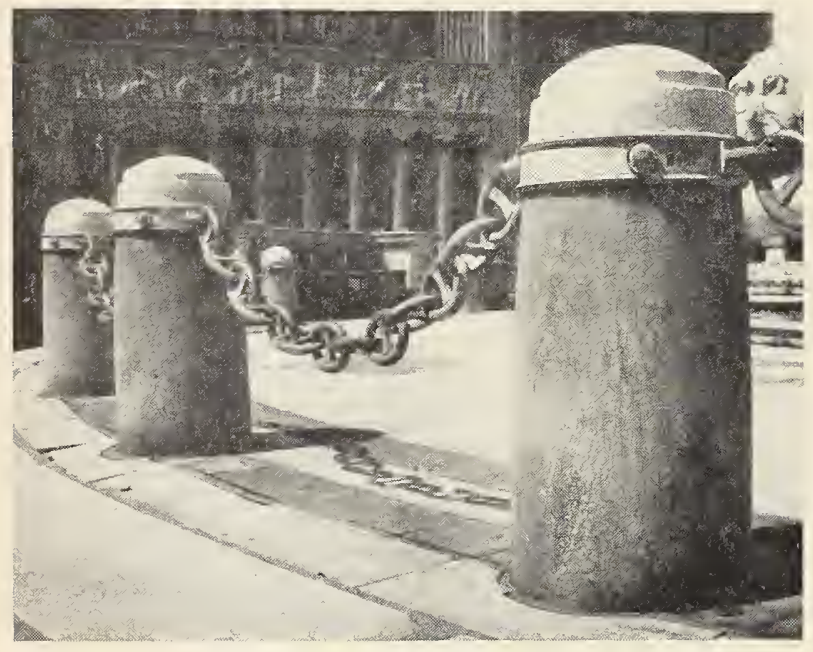

Figure 2. Marble posts surrounding the McKinley Monument at Buffalo, N. Y.

The marble below the bronze collars, forming an attachment for the chain, is badly cracked and discolored brown, whereas that part above the collars is not much changed.

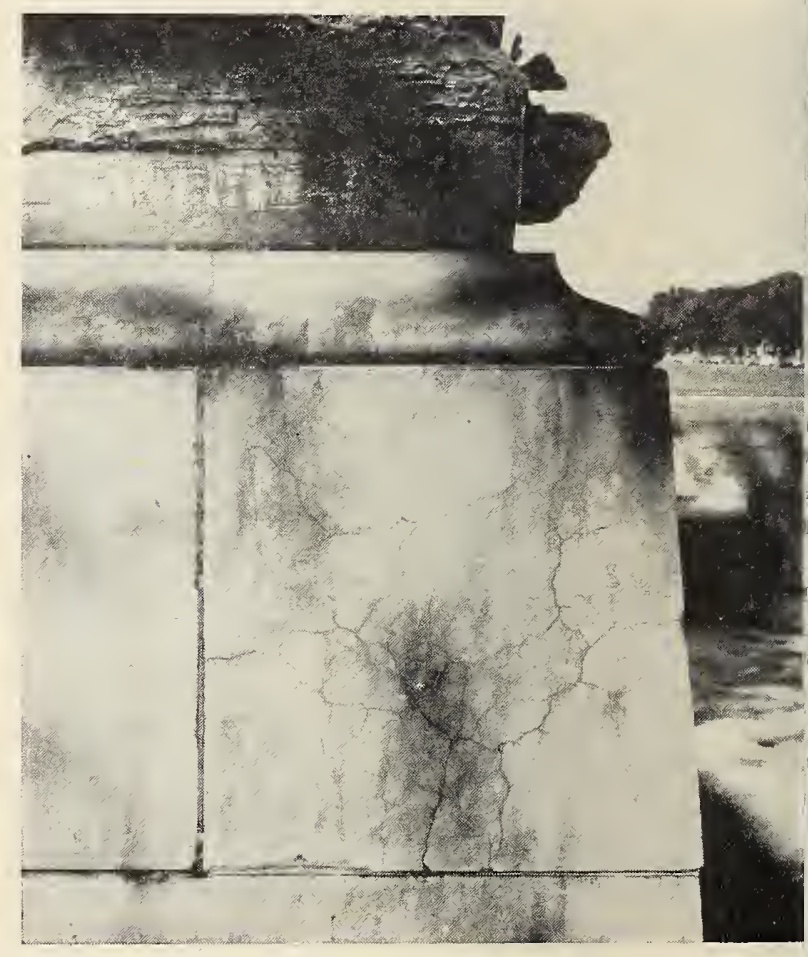

FIGURE 3. Block of badly cracked marble under the nortl statuary group of the Grant Monument showing the wors condution in this structure. 


\section{Description of Materials}

The bronze compositions selected for the tests were (A) 90 parts copper, 8 parts tin, 2 parts lead; (B) 88 parts copper, 10 parts tin, 2 parts zinc; C) 80 parts copper, 3 parts tin, 16 parts zinc, 1 part lead. These were cast into cylindrical ingots by the foundry of the Bureau's Metallurgical Division and turned in a lathe to secure a supply of shavings for the tests.

The Vermont Marble Co. supplied about 100 niarble slabs, 24 by 4.25 by 1.5 in, in size. This firm treated twelve of the slabs by soaking them in molten paraffin to determine if such treatment would prevent discolorations. The marble was a medium-grained, white calcite from a quarry in Colorado. The same marble has been used in several prominent structures, such as the Lincoln Memorial in Washington, D. C. and the Tomb of the Unknown Soldier in Arlington, Va.

\section{Tests on the Fresh Marble}

It was necessary to determine reliable average test vahues of the marble in its original condition for comparison with those obtained after various periods of weathering. As the marble was found to be rather variable from one specimen to another, many tests were made and averaged for each property.

In the flexural-strength determinations, the slabs were first supported near the ends and loaded in the middle. In order to conserve material the two end pieces resulting from the tests on long spans were then tested on shorter spans, the spandepth ratio in the first test being about 14 and in the second about 6.7 , corresponding, respectively, to spans of 21 and $10 \mathrm{in.}$ The modulus-of-rupture values obtained on the 6.7 span-depth ratio averaged about 13 percent higher than those for the 14 ratio, and it became evident that a correction must be made to reduce all values to a common basis. Additional tests were then made on shorter spans in order to derive a curve showing the relation between modulus of rupture and span. This curve was then used to reduce all values to those equivalent for a span of $21 \mathrm{in}$. The curve was also used to correct modulus-ofrupture values obtained on weathered specimens.

Abrasive-resistance tests were made on a testing machine [1] ${ }^{1}$ that determines the abrasion loss under controlled conditions of pressure, speed, and time with a standard abrasive grain used in the dry state. It was known that the rate of abrasion was influenced to some extent by the humidity of the air during the test. ${ }^{2}$ Because it was not feasible to control the humidity of the laboratory,

1 Figures in brackets indicate the literature references at the end of this paper.

${ }^{2}$ High humidity causes the specimen to abrade faster, and low humidity has an opposite effect. Tests made to determine the extent of this effect indicated that a resistance value determined at 12 percent relative humidity would be about 17 percent higher than the value at 30 percent humidity, and if the same specimens were retested at 70 percent humidity, the value would be about 20 percent bolow that at 30 percent humidity. or to make all tests at one humidity, a considerable number of tests were made on one uniform marble at various humiclities to derive corrections for the results on the marble used in the exposures. All values were then corrected to :30-pereent rolative humidity. Sixty-two tests were made on the fresh marble, and the avrrage of all was used for the basis of comparison in later tests.

Alssorption and bulk density values were determined on the specimens used for abrasion tests. Standard methods ${ }^{3}$ were followed, except that the specimens were somewhat smaller than the methods recommend.

Table 1 gives the data on properties of the fresh marble. The histograms in figure 4 show the distributions of the test values. Skewness is in evidence, particularly for the results on abrasive resistance. 'This peculiar distribution of test values and the wide scatter are believed to be mainly responsible for irregularities in some of the curves in figures 8 to 12

TABLE 1. Summary of test data on fresh marble

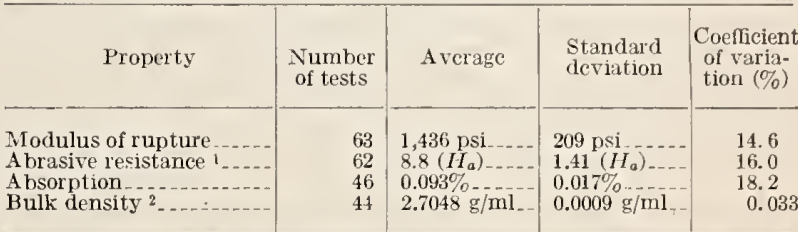

The apparatus and test procedure used to determine the abrasive-resist ance values are described in BS J. Research 11, (1933) RP 612, Wear resistance of natural stone flooring. The symbol $H_{a}$ is used to designate the resistance values.

2 Bulk density is obtained by dividing the dry weight of the specimen in grams by the over-all volume in milliliters, including the volume of the pores.

\section{Description of Exposure Tests}

Figure 5 shows some of the specimens exposed on the limestone coping of a building at the National Bureau of Standards. All specimens were freely exposed, with no protection from the weather or sunlight. Each marble slab was supported on strips of marble attached to the limestone with plastic calking material. The marble slabs were attached to the strips in the same way. The bronze shavings were placed in 22 -gage phosphor bronze boxes at the center of each marble slab and held in position by strips of the metal passing below the marble. Each box contained $1.8 \mathrm{~kg}$ of bronze shavings, and as the boxes were open at top and bottom, rain water could trickle down through the shavings and over the faces of the marble slabs.

There were 15 untreated specimens for each of the 3 bronzes, and 15 slabs of untreated marble were exposed in the same war without bronze in contact for control tests. Six of the 12 specimens treated with paraffin were exposed without bronze, and the other 6 were exposed with bronze on top. There were only 2 specimens of each bronze on the treated marble.

3 ASTM Designation C97-47 

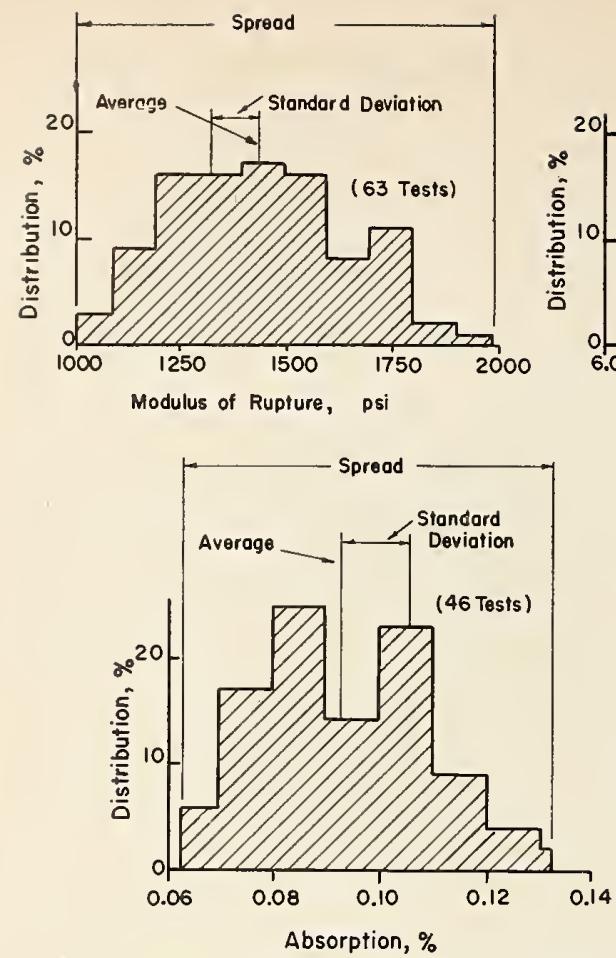
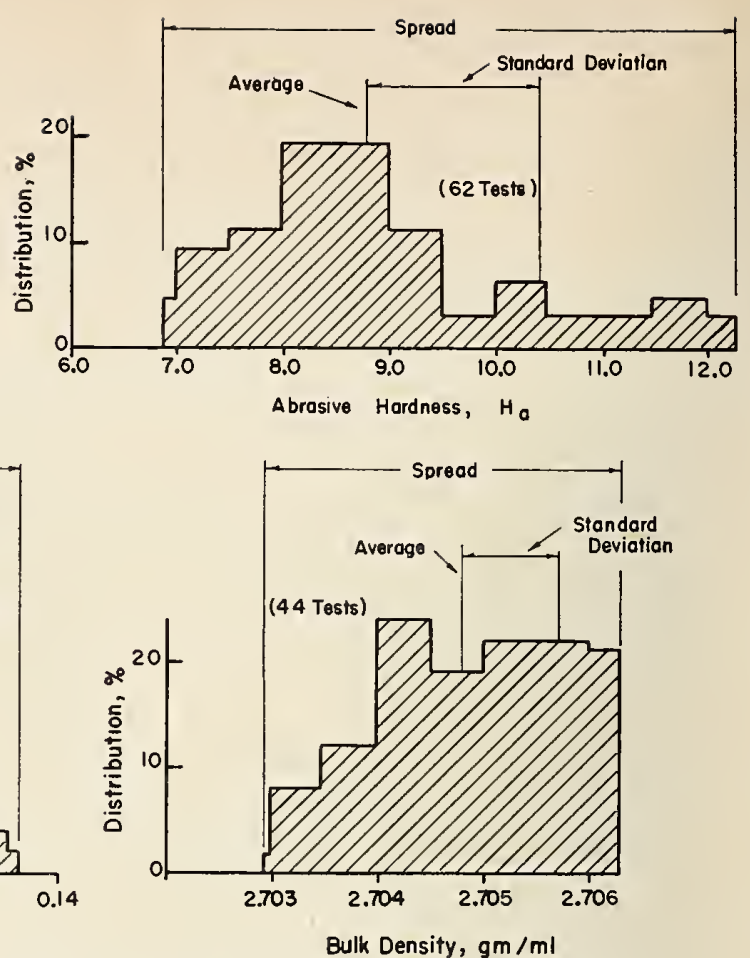

Figure 4. Histograms of the test data on fresh marble used in the exposure tests. This shows a remarkably high variation in the marble from one specimen to another.

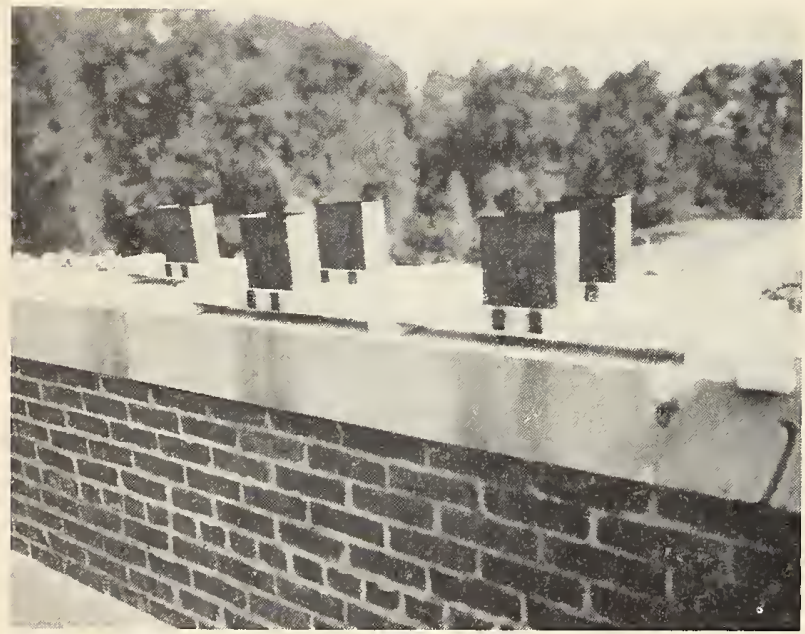

Figure 5. Some of the specimens in the exposure test and the method used for exposing the marble to the wash from bronze shavings.

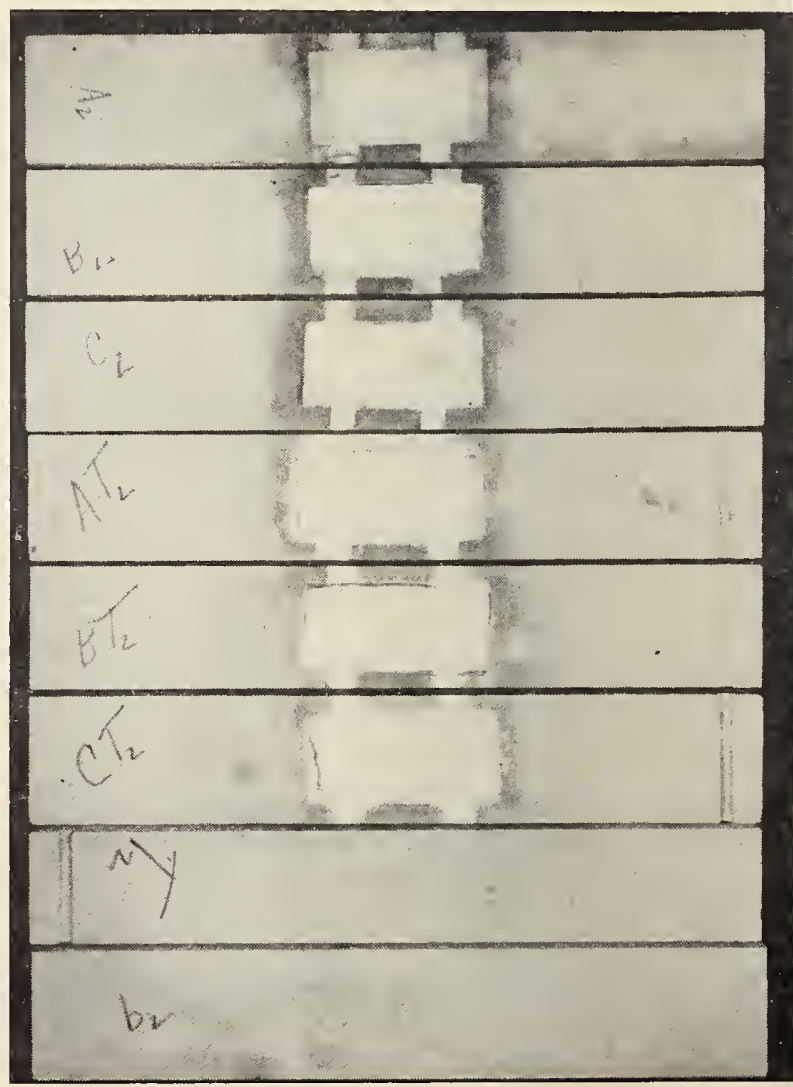




\section{Results of Exposure Tests}

The specimens were examined periodically during the first 2 years for staining effects. Faint-green stains on the marble occurred within a year, and brown stains were noted after 18 monilus. The brown discolorations occurred mainly where there was little shading from the sun; the green appeared on the lower faces of the slabs, under the bronze shavings, and under the bronze strips used to secure the boxes to the marble. The darkest part of the brown stains extended about 2 in. from the boxes, as shown in figure 6 , but in most cases the marble was appreciably darkened on the top face to the ends. The same kinds of stains oceurred on the paraffin-treated marble as on the untreated, but the treatment appeared to retard the staining somewhat. At the end of 5 years there was no appreciable difference in the amount of discoloration on the treated and untreated marble.

Specimens removed for tests at the end of 10 years were found to be warped appreciably. Most of them had sagged under the weights, but two had warped in the opposite direction. The average sag for the specimens exposed to bronzes $\mathrm{A}, \mathrm{B}$, and $\mathrm{C}$ were, respectively, $0.009,0.014$, and 0.017 in. The control specimens sagged more, and the average was $0.033 \mathrm{in}$. One of the treated specimens without bronze sagged $0.25 \mathrm{in}$., and the other warped up at the center 0.024 in. Of the three treated specimens with bronze, one showed no change, one sagged $0.041 \mathrm{in}$., and the third warped upward at the middle $0.020 \mathrm{in}$.

The changes in properties for the different exposure periods are shown in figures 7 to 15 .

At the end of the 5-year period, the marble slabs were broken only in the middle for flexural strength. At the ends of the other test periods, the strength was determined by loading the specimens first in the middle, then breaking the two end pieces by loading them in the middle. The slabs subjected to bronze wash were discolored green at the center, both on top and bottom, so the tests on the long specimens gave the modulus of rupture in a green area, while the breaks at the quarter points were in regions where the specimens were somewhat brown. The curves in figures 7 and 8 indicate that the loss of strength of the marble was least in the green areas, greater in the brown areas, and greatest in the control specimens.

Figures 9 and 10 show the changes in abrasive resistance for different exposures. At the end of the 5-year period, specimens were cut only from the brown areas, but for other periods they were cut from both brown and green areas. The curves are rather variable in trend, but there is some indication that the marble was hardened in the brown areas but not definitely clanged in the green. The apparent increase in hardness for five groups of specimens, including the controls at the final tests, can probably be attributed to the variability of the marble rather than an actual increase. Figures 11 and 12 show that definite increases in absorption occured in brown arcas for all specimens. In the green areas causer by bronze $\Lambda$ the absorption values showed no appreciable change, but in those for bronzes $B$ and $C$ the values were similar to those for the brown areas. All of the increases for the discolored areas were small in comparison with those for the control specimens.

Beeause the bulk density of the marble was much less variable than other properties, it was expected that the changes in this property would give more reliable indications of weathering than strength, hardness, or absorption. The curves in figure 13 are somewhat more regular in trend than those in figures 9 to 12 , inclusive. Decreases in bulk density were more pronouncer in the brown areas than in the green, but changes were much greater in the control specimens.

Some tests were made to determine whether the copper compounds, deposited in the pores of the surface layers, caused an appreciable increase in density of the stained portions. The results indicated that the interior of the marble, not reached by the stains, was appreciably higher in density than the stained portions. Similar indications were obtained for the control specimens when the surface layers and interior portions were tested separately.

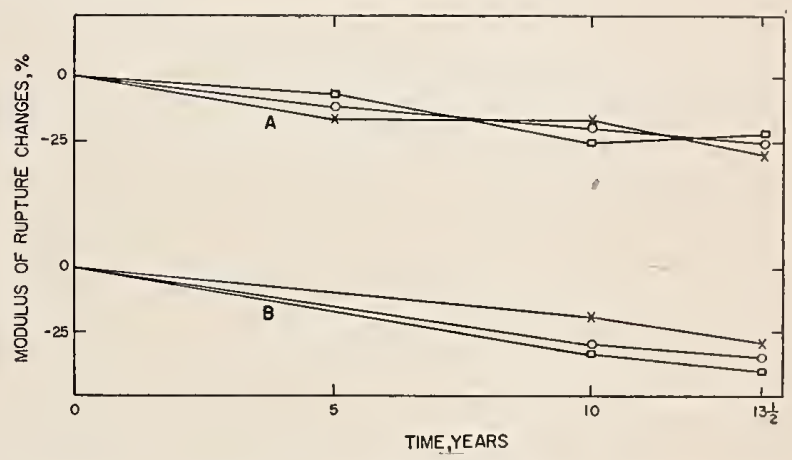

Figure 7. Results of flexure tests after three exposure periods.

The first group of curves show the changes in strength at the center of the specimens (which was mainly in an area of green discoloration), whereas specimens (which was mainly in an area of green discoloration), wherea the lower group shows the strength where the marble was somewhat brown.
, Change at midsection (green areas); $B$, change at quarter-section (hrown areas); $O$, marble with bronze $A$; $X$, marble with bronze $13 ; \square$, marble with bronze $\mathrm{C}$.

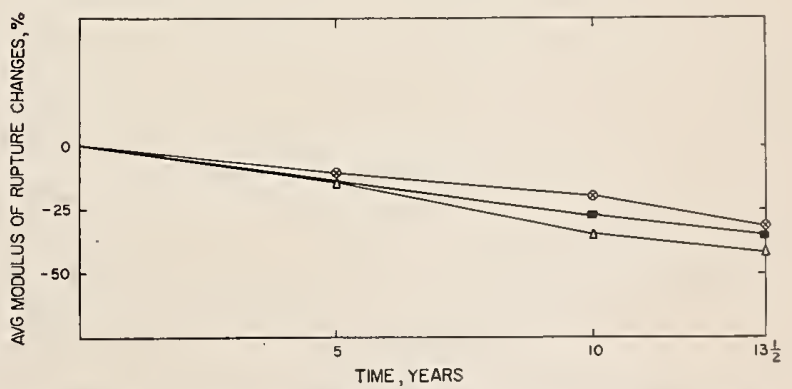

Frgure 8. Average changes in flexural strength in the brown and green areas, along with changes in this property that occurred in the control specimens.

$\otimes$, In green areas; $\boldsymbol{\square}$, in brown areas; $\Delta$, in control specimens. 


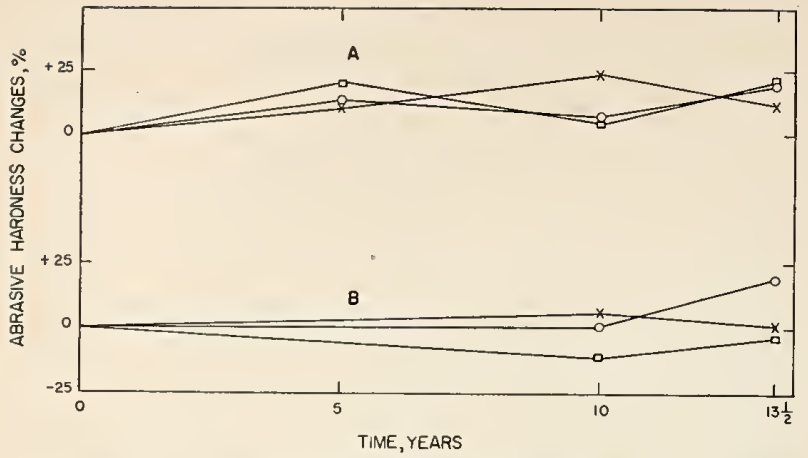

Figure 9. Results of abrasive-hardness tests on marble after three exposure periods.

The variability in trends of these curves is believed to be largly due to variability in tbe marble from one specimen to another. $A$, Changes in brown areas; $\mathrm{B}$, ebanges in green areas; $\mathrm{O}$, marble witb bronze $\mathrm{A} ; \mathrm{X}$, marble with bronze $\mathrm{B}$; $\square$ marble with bronze $\mathrm{C}$.

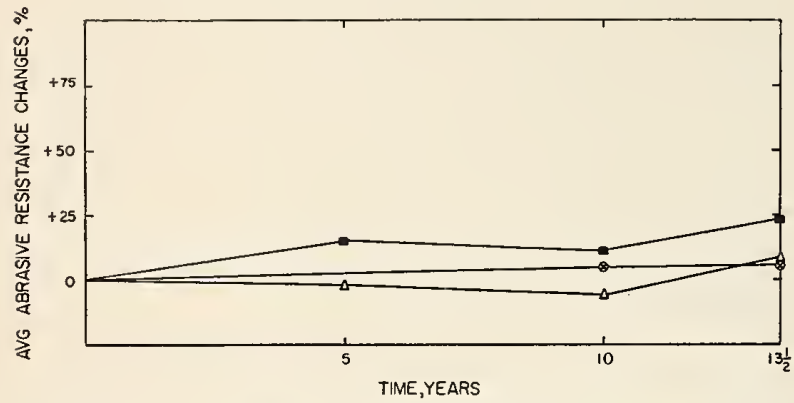

FIGURE 10. Average changes in abrasive hardness in brown and green areas, along with changes in this property that occurred in the control specimens.

$\otimes$, In green areas; $\square$, in brown areas; $\triangle$, in control specimens.

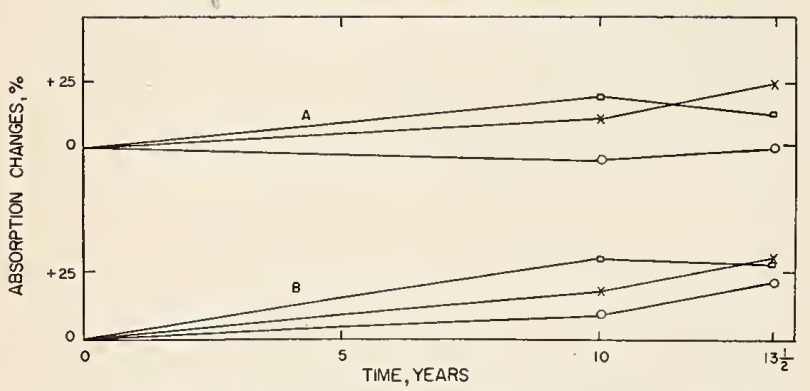

FIGURE 11. Changes in absorption of the marble in brown and green areas for two exposure periods.

$\mathrm{A}$, absorption in green areas; $\mathrm{B}$, absorption in brown areas: $\mathrm{O}$, marble witb bronze $\mathrm{A} ; \mathrm{X}$, marble with bronze $\mathrm{B} ; \square$, marble witb bronze $\mathrm{C}$.

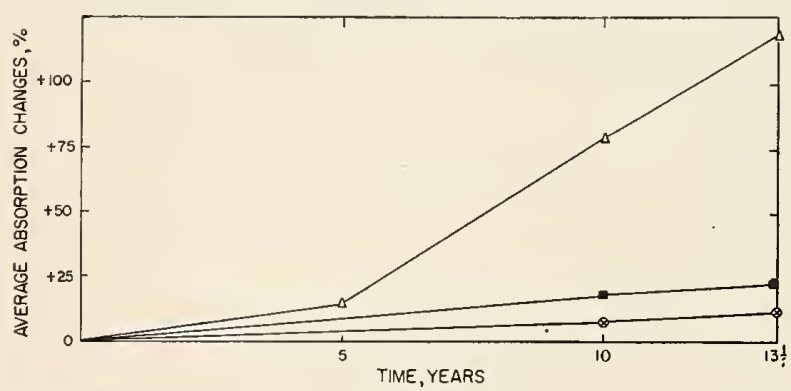

Figure 12. Average changes in absorption for brown and green areas, along with the changes that occurred in this property in the control specimens.

$\otimes$, In green areas; $\mathbf{\omega}$, in brown areas, $\Delta$, in control specimens.

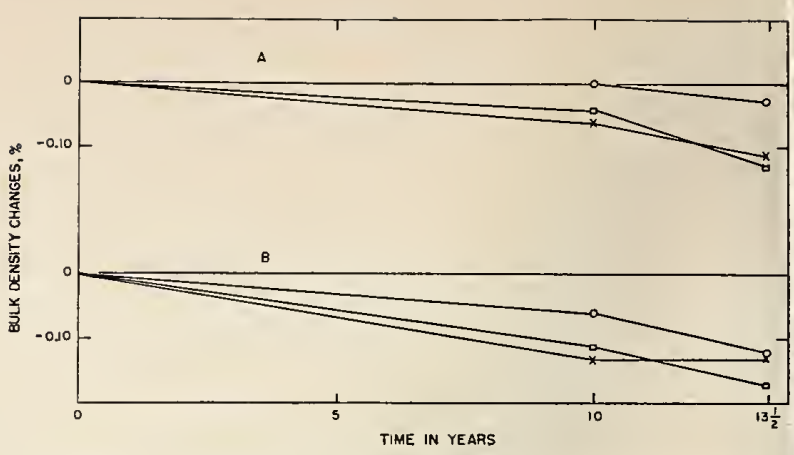

Figure 13. Changes in bulk density of the marble for two exposure periods.

$A$, Change in green areas; $B$, cbange in brown areas; 0 marble witb bronze $A ; \mathrm{X}$, marble with bronze $\mathrm{B} ; \triangle$, marble with bronze $\mathrm{C}$.

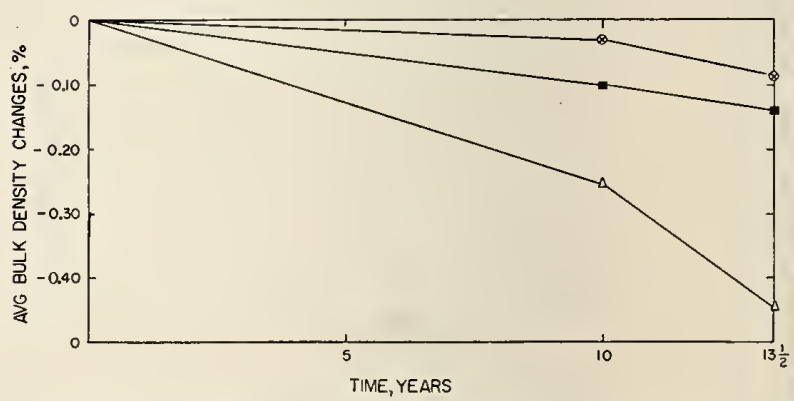

Figure 14. Average changes in bulk density for the brown and green areas along with the changes that occurred in this property in the control specimens.

$\otimes$. In green areas; $\mathbf{n}$, in brown areas; $\triangle$, in control specimens.

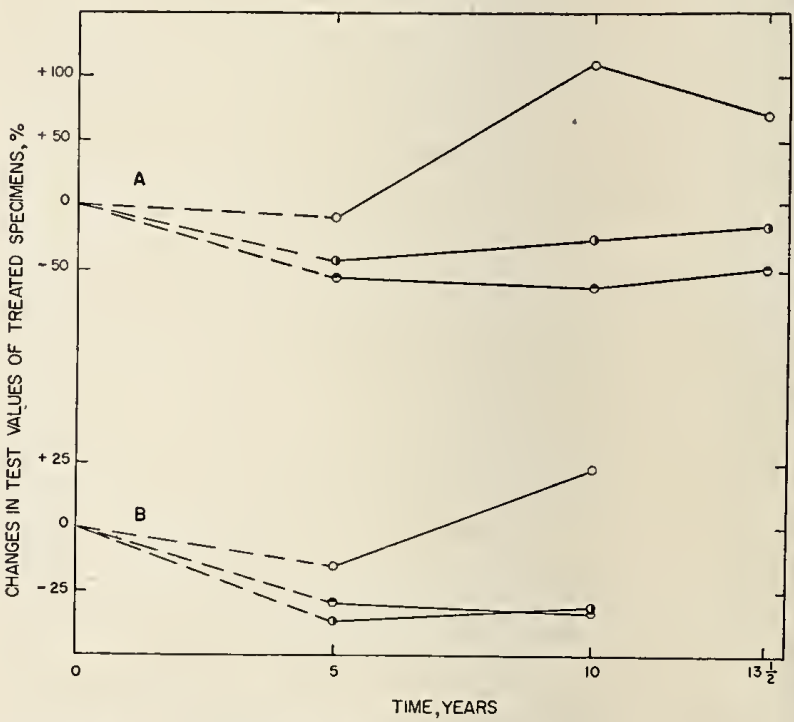

FIgure 15. Changes in strength, abrasive hardness, and absorpition of the treated specimens.

The treatment appeared to accelerate the weathering action rather tban

$A$, Not exposed to bronze; $B$, exposed to bronze; $O$, absorption; $O$, abrasive resistance ; $\theta$, flexural. 
Changes in flexural strength, abrasive resistance, and absorption for specimens treated with paraffin are shown in figure 15. Bulk-density clianges were determined, but they were small in comparison with those of the other properties and are not shown in the graphs. It was assumed that the only effect of the treatment on the properties of the marble would be to reduce the absorption. For this reason, and the fact that only a few specimens were available, no tests were made before exposure. However, the low flexuralstrength and abrasive-resistance values obtained at the end of the first exposure period indicate that there was a pronounced effect of the treatment on these properties as soon as the treatment was applied. As tirere rvere no data for the original test values, the curres in figure 15 are shown in dashed lines, for the first 5 years, starting from the zero point.

\section{Observations on Various Marbles Exposed to Bronze}

A few inspections of various marbles in monuments and buildings were made to determine if all marbles are affected alike when exposed to the wash from bronze. All of these installations were in Washington, D. C., except the McKinley Monument. No records were available to definitely identify the marbles in the monument bases as to source or common names. In the following notes effort is made to identify these marbles from their appearance, but there is some doubt as to the correct designations of those in the Lafarette and Rochambeau monuments. The compositions of the bronzes used in the various castingswere not known. (Numerals in parenthesis following the names of the structures indicate the rears of erection.)

Georgia Marble... The Corcoran Art Gallery (1906) has two bronze lions, either side of the entrance, mounted on pedestals of coarsely crystalline, calcite marble from Georgia. Green stains on the marble are abundant, but no brown discolorations or pronounced weathering was found. A few cracks in a corner block of the south pedestal appear to be due to a defect in the marble.

Two large bronze lanterns are mounted on marble pedestals in front of the Pan American Building (1908). The pedestals are Georgia marble, in part, but they show no appreciable deterioration. Georgia marble steps abutting on the pedestals show small areas of brown discoloration and a minor amount of cracking.

Alum Marble. The coarsely crystalline calcite marble, formerly quarried at Texas, Md., was used in the bases of two equestrian monuments. These are the Jackson Monument(1853) in Lafayette Square and the Washington Equestrian Monument (1860) in Washington Circle. Neither of these shows prominent staining of any kind, and apparently the marble is in good condition. Some cracks in one corner of the latter appear to be due to a fauly block raflee than a weathering effect.

Carrara Marble. 'The Lafayette Monument (1891), in Lafayelte Square, is believerl to be Carrara inarble. It lias a large amount of bronze mounterl on a central perlestal of marble. Both green and brown stains on the marble are abundant. Near the base, where the brown stains ale most pronounced, there are sereral large racks in the marble.

Beaver Dum Marble. 'The Rochambeau Monument, (1902) in Lafarette Square, has several bronze figures mounted on a white marble, which appears to be the Beaver Dam dolomite. Discolorations on the marble are shight, and there secms to be no deterioration.

Termont White Marble: The Grant Monument (1922) shown in figure 1 consists of seren marble bases supporting large bronze figures. Sereral blocks have prominent brown stains, accompanied by cracking of the marble. The worst condition is shown in figure 3 , but many blocks appear to be in good condition. The corner block under the south group is projecting considerably over the edge of the block below. 'This is believed to indieate that the injured block has undergone a swelling action.

This same marble was used in the American Red Cross Building on Seventeenth Street. 'Two bronze lampposts are attached to the marble cheek walls at the main entrance. One block in the north cheek wall is showing a condition of incipient cracking similar to the more advanced stage shown in figure 3 . None of the other blocks near these lamp posts show a similar condition.

The McKinler Monument, in Buffalo, $\mathrm{N}$. I. (1907), is surrounded by sereral marble posts, and near the top of each post is a bronze collar supporting a bronze chain. Figure 2 illustrates how seriously the marble is cracked. Abore the collars the marble appears to be in good condition. When this structure was examined about 20 years ago, the brown stains were confined to a few inches below the collars, and incipient cracking was risible in these discolored areas. This seems to prove that the deterioration was caused by the bronze rather than some substance coming up from below.

Tennessee Marble: The only case examined where this marble is exposed to the wash from bronze is at the National Gallery of Art. Small lampposts are mounted on the marble at the east and west ends of the building. Only green stains were found, and there appeared to be no deterioration of the marble.

Colorado Yule Marble: In the Lincoln Memorial (1916) this marble forms the exterior. The only part of the marble in contact with bronze on the exterior is on the coping. Bronze cramps were used to anchor the coping blocks together, and they were sunk into the marble about $1 / 2 \mathrm{in}$. below the surface. The recess abore the bronze was filled with mortar. When this was examined, some of the mortar had weathered away, and in 
other cases the mortar had shrunk away from the marble enough to expose the bronze to rain water. All of the joints were examined, and only three were showing the characteristic staining and cracking of the marble. More cases were found where the cramps had broken off the end of blocks because of temperature strains.

South Dover Marble: This dolomite marble forms the exterior of the National Academy of Science Building. The building has bronze window frames, a copper roof, and considerable ornamental copper work on the coping. This case is of value in comparing the effects of bronze and copper. Both green and brown stains occur in abundance even on the marble steps at the front, which are about $16 \mathrm{ft}$ from the building. Crack formations often occur in the brown discolored areas, and some of the marble is sugaring. It is evident that copper is the element in the bronze that causes discolorations, and the stains from this metal may be either green or brown. Sugaring of the marble was found where the marble was exposed only to the wash from copper and also where both metals may have had an effect. This case also shows that the dolomites may be as much affected by such conditions as calcite marbles.

Most of the structures described above were exposed to the sun for at least half of the time. In the Lafayette and parts of the Grant monuments the marble was shaded during a large portion of the time.

No definite relations could be found in these observations between the locations of brown stains and the exposure to sunlight such as indicated by the exposure tests. Brown discolorations were found where the marble was shaded most of the time, and both green and brown stains appeared where there was very little shading.

\section{Discussion of Results}

The data obtained in the exposure tests on one particular marble show that this marble was stained both green and brown by the wash from bronze. It weathered appreciably faster in the brown areas than in the green, and faster still in the control specimens. The weathering in all cases was so mild that crack formations did not occur. The following reasons probably account for this behavior: (1) This marble was one of the more resistant varieties, and (2) the exposure period was relatively short.

Information obtained from observations on structures indicates plainly that some marbles are not seriously affected by the wash from bronze for many years, whereas others show crack formations under such conditions in less than 20 years.

In the following discussion an effort is made to interpret the results with reference to data available on weathering processes.

\subsection{Exposure Tests}

Each set of curves (figs. 4, and 7 to 15) is based on differences in test values between the fresh marble and weathered marble. The average values of strength, abrasive resistance, absorption, and bulk density on the fresh marble were determined from numerous tests, and are believed to be reliable; but because the amount of marble was limited, it was possible to determine the corresponding values after each period of weathering on only 5 to 6 specimens. Chance selection of a few specimens from a material that varies considerably does not give as reliable average values for the properties as a larger number would. This probably accounts for the fact that some of the curves are irregular in trend, especially those for abrasive resistance.

\section{a. Untreated Specimens}

The most prominent feature of the exposure tests was that the control specimens weathered more rapidly than those exposed to the wash from bronze. In view of the unmistakable fact that some marbles deteriorate rapidly under bronze but are durable under normal conditions, it is important to find some explanation for the variable performance. A possible explanation is that copper compounds forming in the pores may act, to some extent, as an added binding material during the early period of exposure. After a larger amount has accumulated in the pores, it might act as a disiupting force. It is well known that iron compounds form a binding material in various types of rocks. However, rock strata are commonly formed under high pressures from all directions, and under such conditions the infiltration of extraneous matter could not disrupt the stone. Conditions in a building or monument are quite different because the blocks are not restrained on the exposed face.

Tests on numerous samples of marble after weathering under normal conditions have shown that prominent increases in absorption, and significant decreases in bulk density occur. Decrease in strength are appreciable, but little information is available on changes in abrasive resistance during weathering. Stone workers believe that exposure to the weather increases the hardness of stone. In the abrasion test, it seems logical to believe that the resistance of specimens would not be greatly changed unless the individual crystals undergo deterioration or unless the bond between grains becomes so weak that abrasion would result in crumbling the marble. Examination of sugared marble after long periods of exposure indicates that the individual grains do not suffer appreciable deterioration. For this reason it is believed that absorption, strength, and bulk-density determinations are of more value for indicating the amount of weathering than abrasive resistance. In the tests on specimens after weathering under bronze, the results for these three properties are reasonably concordant. 


\section{b. Paraffin-Treated Specimens}

Tests on paraffin-treated specimens were not planned in the original program, but some specimens were included at the request of the marble producer who supplied the specimens. The limited number of pieces precluded a more thorough study of the value of the treatment. It was known that this treatment was quite effective in sealing the pores of sandstones and limestones of the more porous varieties, and that the treatment deteriorated slightly during an exposure period of 10 rears [2]. No previous data were available to indicate that the treatment reduces the strength and abrasive resistance of stone.

The effect of the treatment. on strength was thought to be due to the wax acting as a lubricant between crystals. In order to check this assumtion, some specimens were soaked in a light lubricating oil until it had penetrated entirely through the marble. Flexure tests were then made on the specimens, and the resulting modulus of rupture was 30 percent lower than the average for fresh untreated marble. As the fracture in this test is mainly between crystal surfaces, it is concluded that both the wax and oil caused a marked reduction in the bond between crystals.

When specimens were cut from the treated slabs, they had a wax-penetrated layer at top and bottom, with a layer between that was not penetrated. When these specimens were immersed in water the portions between penetrated layers could absorb as readily as untreated marble. For this reason the absorption results are useful only for indicating the rate of deterioration of the treatment.

The absorption of the control specimens in the treated group increased considerably faster between 5 and 10 years than the controls in the untreated group. The apparent decrease in absorption rate between 10 and $13 \frac{1}{2}$ years might be explained by the fact that the depth of penetration in different parts of the marble was variable. It could be scen that the depth of penetration was variable when the slabs were broken in flexure and that the depth varied from $1 / 4$ to $3 / 8$ in. The number of specimens available was too limited to get more reliable average values.

The curves indicate that there was a slight increase in abrasive resistance of the marble after 5 years for the control specimens and also for those exposed to bronze. 'The flexural strength decreased slightly in both groups between 5 and 10 years, but in the control group there was a slight increase after 10 years. In general, the tests indicate that the control specimens deteriorated more rapidly than those exposed to bronze. Apparently there was some improvement in qualities of the marble as the wax weathered away.

Considerable confidence has been manifested in the paraffin treatment in the past and it has been used as a preservative on various materials, such as the granite in Cleopatra's Needle and on sandstone buildings in New York City [3]. The expo- sure tests as well as others [2] have indicated that the life of the treatment is short compared to the normal life of most stones. Probably the effects on the strength and abrasive resistance of stone would not be a serious consideration.

\section{c. Warping of Marble}

Marble slabs lrave been observed to warp under various conditions of exposure. The direction of warpage seems to be determined by gravity in some cases, but not all. 'The phenomenon is probably an intergranular effect and evirlently has some connection with tempcrature changes. It lias been reported that stoneworkers sometimes bend marble slabs under lot water to make them conform to a desired curve. Adams [4] has proved that marble can be made to assume new shapes by subjecting it to high pressures in closed lieated containers.

The comparatively large amount of warping that occurred in the control specimens that have been trcated with molten paraffin seems to indicate that the wax facilitated slippage between crystals. The fact that marble sometimes warps upward against the force of gravity has never been satisfactorily explained.

\subsection{Observations on Structures}

Inspection of various marbles exposed to the wash from bronze indicates prominent differences in their resistance to deterioration. Three of the eight marbles that were examined had developed brown discolorations and were showing crack formations. Another marble was little affected with eithcr green or brown stains, and no significant amount of deterioration could be found on the marble of two monuments in which it was used, although both of these were nearly 100 years old. One dolomite marble in a monument base for 50 years was in good condition whereas another marble of the same type in a building 35 years old was showing crack formations and occasional sugaring in the brown areas. Calcite marbles, which are considered to have satisfactory durability under ordinary conditions of use, were found in two monuments where they were exposed to the wash from bronze. In both cases there were many blocks showing advanced stages of weathering for portions affected by dark stains. These marbles seemed to be more readily affected by such conditions than any examined. One of these marbles in a building 20 years old was exposed to the action of bronze under lampposts. One block showed plainly the beginning of the action that had reached an advanced stage in the two monuments in less than 40 years.

The inspections indicate that some of the marbles readily develop green discolorations due to the wash from bronze, but in these there appears to be no serious weathering action. In larger structures, where several blocks of marble from the same source were used, it was noted that different 
blocks have various degrees of resistance to deterioration. The proximity of marble to bronze seems to be unimportant, and frequently blocks in direct contact with the metal were in good condition, whereas others several feet away were badly cracked. Mortar is readily discolored a uniform shade of green, and in some instances it presented a prominent contrast with the adjoining marble. No case was found where the mortar was stained brown, and the green staining matter appeared to have no detrimental effect.

\subsection{Effect of Infiltrating Matter}

It has long been known that marble undergoes some change in structure when it is subjected to cycles of heating and cooling. Souder and Hidnert [5], in determining the thermal expansion of various marbles, found that when a specimen is measured at room temperature then heated to $100^{\circ} \mathrm{C}$, the rate of expansion increases as the temperature increases. Also, when the temperature is lowered to the starting point, the specimen does not return to its original length but retains an increment of growth. Each repetition of the temperature cycle resulted in an additional increase in length. Such effects are probably due to the peculiar expansion characteristics of calcite crystals. The thermal coefficient has been determined as $22 \times 10^{-6}$ per deg $\mathrm{C}$ along the principal axis and $-4 \times 10^{-6}$ per $\operatorname{deg} \mathrm{C}$ normal to that axis [6]. The simultaneous expansion in one direction and contraction in another for each change in temperature evidently causes stresses within a closely packed mass of crystals like marble and a complicated condition of stresses and movements among the crystals, which results in slippage along contiguous surfaces. The fact that marble takes on an increment of growth during succeeding temperature cycles indicates that readjustment of the movements between crystal surfaces is not completed during the first cycle.

Different marbles show appreciable differences in rates of growth for repeated cycles of heating and cooling, but generally the rates decrease with the number of cycles. It has been found that if the marble is heated while standing in a small quantity of a difute salt solution, such as gypsum, the grow th of the specimen is greatly increased. Repeated cycles under such conditions result in an almost constant rate of growth of the specimen. If lime water is used instead of the gypsum solution, most marbles show a similar effect, but the rates of growth are somewhat lower than when gypsum is used. In this test there is a pronounced difference in rates of growth for different marbles, and a fair degree of correlation has been found between these rates and the durability of different marbles [7].

The reason for this behavior is believed to be that, during each heating, some of the solid matter in solution is carried into the pores while the marble is under stress. This solid matter acts as an obstacle to readjustment during the cooling and thus causes a more rapid growth.
It seems likely that any solid matter carried into the pores of marble would have a similar effect. One case has been noted where a block of marble was stained green from vegetation. The block crumbled at the edges during an exposure of about 15 years. The same kind of marble is known to be durable under normal conditions of exposure.

Studies on old marble structures in Athens by Sofianopoulos [8] indicate that most of the deterioration is in discolored areas where the marble is somewhat sheltered from the cleaning effects of rains. He states that these areas are covered with a layer of fine dust containing clay, silica, and soot, which holds moisture and atmospheric gases by absorption. This authority found evidence that the byproducts of chemical reactions gave rise to discoloration and mechanical forces that exert a destructive action.

Such performance seems to offer an explanation of the effect of bronze stains on marble. It does not explain why brown stains produce a more severe condition than green stains. Possibly the specific gravity of the solid matter may be a consideration. The specific gravity of cupric oxide, which seems to be the main constituent of the brown staining matter, is approximately 6 , and that of malachite (basic cupric carbonate) is 4 . A somewhat analogous effect was found in experiments with gypsum and calcium hydroxide; the specific gravity of the first is 2.3 , and that of the other is 2.0. However, the difference in solubility of these calcium compounds evidently causes a larger amount of the gypsum to be carried into the pores.

\section{Summary}

The peculiar performance of different marbles when exposed to various conditions of use tends to emphasize the need for a more intensive study of the destructive forces involved in weathering phenomena. The writers have set forth their interpretation of the results obtained in experimental studies, with due regard to the unmistakable evidences shown by the performance of different marbles in structures. It is possible that the anomalous experimental results are due to some factor, such as the mortar between blocks in masonry, which plays an unexpected part in the weathering process and was not reproduced in the exposure tests. The findings should emphasize the desirability of diverting the wash from bronze away from the marble wherever possible. Inasmuch as the resistance of different marbles to such conditions cannot be feasibly determined in the laboratory, the selection of material should be based on past performance.

The following conclusions are believed to be justified:

1. Rain water flowing over bronze work and then over marble affects different marbles in different ways. Marbles from some sources are discolored green, and those from other sources develop both green and brown stains. 
2. Marbles that develop only green stains, appear to withstand weather action as well under bronze as under normal exposures, whereas some of those that develop brown stains deteriorate more rapidly in the brown arcas.

3 . Copper is the main element in bronze that causes stains and deterioration of the marble. The green discolorations probably result from the formation of basic cupric carbonate in the pores of marble, whereas cupric oxide forms the main portion of the brown stains. Marble exposed to the splash below copper roofs develops the same kinds of discolorations that occur under bronze.

4. Dolomite marbles are affected in the same way as calcite marbles, and different dolomites show different degrees of resistance to the action of the wash from bronze.

5. Treatment of the marble with molten paraffin to seal the pores does not prevent discolorations due to bronze wash, except for 2 or 3 years. This treatment reduces the flexural strength and abrasive resistance of marble.

6 . Wherever bronze or copper is mounted on marble, an effective means should be provided for diverting the wash from the metal away from the marble.

\section{References}

[1] Daniel W. Kessler, Wear resistance of natural stonc flooring, 13S J. Research 12, 35.3 (1933) TRPf6].

[2] Daniel W. Kessler, Fxterior waterproofug materials for masoney, N'BS $\%$. Research 14, 317 (193i) RP771.

[3] G. P. Merrill, Stones for building and decoration, p494 (John Wiley \& Sons, New York, N. Y., 1908).

[4] Frank Dawson Adams, An experimental investigation into the flow of marble, Trans. Royal Soc. (Lonrlon) [A] 195, 363-401 (1901).

[5] Wilmer H. Souder and Peter Hidnert, Thermal expansion of insulating materials, BS Sci. Pap. 15, 387 (1918) S352.

[6] Walter M. Johnson and Willard H. Parsons, 'Thermal expansion of concrete aggregate materials, NT3S J. Research 32, 101 (1944) RP1578.

[7) Daniel W. Kessler, A new durability test for marble, Am. Soc. for Testing Materials, Bul. No. 159, p. 45 (July 1949).

[8] A. J. Sofianopoulos, Conservation of ancient marble monuments, J. Chem. Educ, 28, 79 (1951).

Wasmington, January 26, 1953. 




\title{
BUILDING MATERIALS AND STRUCTURES REPORTS
}

\author{
[Continued from cover page $\mathrm{ir}$ ]
}

BMS32 Structural Properties of Two Brick-Concrete-Block Wall Constructions and a Concrete-Block Wall Construction Sponsored by the National Concrete Masonry Association

BMS33

BMS34

BMS35

BMS36

BMS37

BMS38

BMS39

BMS40

BMS41

BMS42

BMS43

BMS44

BMS45

BMS46

BMS47

BMS48

BMS49

BMS50

BMS51

BMS52

BMS53

BMS54

BMS55

BMS56

BMS57

BMS58

BMS59

BMS60

BMS61

BMS62

BMS63

BMS64

BMS65

BMS66

BMS67

BMS68

BMS69

BMS70

BMS71

BMS72

BMS73

BMS74

BMS75

BMS76

BMS77

BMS78

BMS79

BMS80

BMS81

*Out of print.
Performance Test of Floor Coverings for Use in Low-Cost Housing: Part $1 \ldots$

Stability of Sheathing Papers as Determined by Accelerated Aging.

Structural Properties of Wood-Frame Wall, Partition, Floor, and Roof Constructions With "Red Stripe" Lath Sponsored by The Weston Paper and Manufacturing Co Floors, Sponsored by Palisade Homes ctural Properties of Two "Dunstone" Wall Constructions Sponsored by the W. E. Dunn Manufacturing Co Structural Properties of a Wall Construction of "Pfeifer Units" Sponsored by the

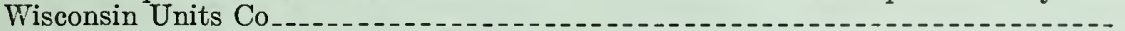

Structural Properties of a Wall Construction of "Knap Concrete Wall Units" Sponsored by Knap America, Inc

Effect of Heating and Cooling on the Permeability of Masonry Walls. Structural Properties of Wood-Frame Wall and Partition Construction With "Celotex" Insulating Boards Sponsored by The Celotex Corporation Performance Test of Floor Coverings for Use in Low-Cost Housing: Part 2-1 Surface Treatment of Steel Prior to Painting Air Infiltration Through Windows

Structural Properties of "Scott-Bilt" Prefabricated Sheet-Steel Constructions for Walls, Floors, and Roofs Sponsored by The Globe-Wernicke Co Structural Properties of Prefabricated Wood-Frame Constructions for Walls, Partitions and Floors Sponsored by American Houses, Inc.

Sponsored by the Homasote Co
Metallic Roofing for Low-Cost House Construction

Stability of Fiber Building Boards as Determined by Accelerated Aging......... * Structural Properties of "Tilecrete Type A" Floor Construction Sponsored by the Tilecrete Co _.............

Effect of Ceiling Insulation Upon Summer Comfort

Structural Properties of a Masonry Wall Construction of "Munlock Dry Wall Brick" Sponsored by the Munlock Engineering $\mathrm{C}_{0}$ Effect of Soot on the Rating of an Oil-Fired Heating Boiler

Effects of Wetting and Drying on the Permeability of Masonry Walls A Survey of Humidities in Residences Roofing in the United States-Results of a Questionnaire Strength of Soft-Soldered Joints in Copper Tubing . . . Properties of Adhesives for Floor Coverings Bricks Produced in the United States Structural Properties of Two Nonreinforced Monolithic Concrete Wall Constructions--
Structural Properties of a Precast Joist Concrete Floor Construction Sponsored by the Portland Cement Association.

Moisture Condensation in Building Walls

Solar Heating of Various Surfaces

Methods of Estimatiog Loads in Plumbing Systems

Plumbing Manual_...

Structural Properties of "Mu-Steel" Prefabricated Sheet-Steel Constructions for Walls, Partitions, Floors, and Roofs, Sponsored by Herman A. Mugler_....... $15 \phi$

Performance Test for Floor Coverings for Use in Low-Cost Housing: Part 3

Stability of Fiber Sheathing Boards as Determined by Accelerated Aging

Asphalt-Prepared Roll Roofings and Shingles _.

Fire Tests of Wood- and Metal-Framed Partitions

Structural Properties of "Precision-Built, Jr." Prefabricated Wood-Frame Wall Construction Sponsored by the Homasote Co

Indentation Characteristics of Floor Coverings

Structural and Heat-Transfer Properties of "U. S. S. Panelbilt" Prefabricated SheetSteel Constructions for Walls, Partitions, and Roofs Sponsored by the Tennessee Coal, Iron \& Railroad Co Survey of Roofing Materials in the North Central States.

Effect of Outdoor Exposure on the Water Permeability of Masonry Walls Properties and Performance of Fiber Tile Boards Structural, Heat-Transfer, and Water-Permeability Properties of Five Earth-Wall

Water-Distributing Systems for Buildings.

Performance Test of Floor Coverings for Use in Low-Cost Housing: Part 4 -

Field Inspectors' Check List for Building Constructions (cloth cover, $5 \times 71 / 2$ inches) $--30 \phi$

[List continued on cover page IV] 


\section{BUILDING MATERIALS AND STRUCTURES REPORTS}

\section{[Continued from cover page III]}

BMS82

BMS83

BMS84

BMS85

BMS86

BMS87

BMS88

BMS89

BMS90

BMS91

BMS92

BMS93

BMS94

BMS95

BMS96

BMS97

BMS98

BMS99

BMS100

BMS101

BMS102

BMS103

BMS104

BMS105

BMS106

BMS107

BMS108

BMS109

BMS110

BMS111

BMS112

BMS113

BMS114

BMS115

BMS116

BMS117

BMS118

BMS119

BMS120

BMS121

BMS122

BMS123

BMS124

BMS125

BMS126

BMS127

BMS128

BMS129

BMS130

BMS131

BMS132

BMS133

BMS134

BMS135

BMS136

BMS137
Water Permeability of Walls Built of Masonry Units

Strength of Sleeve Joints in Copper Tubing Made With Various Lead-Base Solders...

Survey of Roofing Materials in the South Central States.Temperature

Structural, Heat-Transfer, and Water-Permeability Properties of "Speedbrik" Wall

Construction Sponsored by the General Shale Products Corporation-
A Method for Developing Specifications for Building Construction-Report of Subcommittee on Specifications of the Central Housing Committee on Research, Design, and Construction

Recommended Building Code Requirements for New Dwelling Construction With Special Reference to War Housing Structural Properties of "Precision-Built, Jr." (Second Construction) Prefabricated Wood-Frame Wall Construction Sponsored by the Homasote CoStructural Properties of "PHC" Prefabricated Wood-Frame Constructions for Walls, Floors, and Roofs Sponsored by the PHC Housing Corporation. ........ A Glossary of Housing Terms Fire-Resistance Classifications of Building Constructions Water Permeability and Weathering Resistance of Stucco-Faced, Gunite-Faced, and "Knap Concrete-Unit" Walls

Tests of Cement-Water Paints and Other Waterproofings for Unit-Masonry Walls.Properties of a Porous Concrete of Cement and Uniform-Sized Gravel Experimental Dry-Wall Construction With Fiber Insulating Board.... Physical Properties of Terrazzo Aggregates

Structural and Heat-Transfer Properties of "Multiple Box-Girder Plywood Panels" for Walls, Floors, and Roofs

Relative Slipperiness of Floor and Deck Surfaces Strength and Resistance to Corrosion of Ties for Cavity Walls Painting Steel

Measurements of Heat Losses From Slab Floors

Structural Properties of Prefabricated Plywood Lightweight Constructions for Walls, Partitions, Floors, and Roofs Sponsored by the Douglas Fir Plywood Association Paint Manual with particular reference to Federal Specifications Laboratory Observations of Condensation in Wall Specimens. Building Code Requirements for New Dwelling Construction Temperature Distribution in a Test Bungalow With Various Heating Devices... Strength of Houses: Application of Engineering Principles to Structural Design Paints for Exterior Masonry Walls Performance of a Coal-Fired Boiler Converted to Oil Properties of Some Lightweight-Aggregate Concretes With and Without an Airentraining Admixture.

Fire Resistance of Structural Clay Tile Partitions Temperature in a Test Bungalow With Some Radiant and Jacketed Space Heaters..A Study of a Baseboard Convector Heating System in a Test Bungalow Preparation and Revision of Building Codes. Fire Resistance of Walls of Lightweight Aggregate Concrete Masonry Units..... Stack Venting of Plumbing Fixtures Wet Venting of Plumbing Fixtures Fire Resistance of Walls of Gravel-Aggregate Concrete Masonry Units... Investigation of Failures of White-Coat Plasters Physical Properties of Some Samples of Asbestos-Cement Siding Fire Tests of Wood-Framed Walls and Partitions With Asbestos-Cement Facings....Fire Tests of Steel Columns Protected With Siliceous Aggregate Concrete....... Stone Exposure Test Wall

The Self-Siphonage of Fixture Traps Effect of Aging on the Soundness of Regularly Hydrated Dolomitic Lime Putties.. Atmospheric Exposure Tests of Nailed Sheet Metal Building Materials_..._...... Fire Endurance of Shutters for Moving-Stairway Openings Methods and Equipment for Testing Printed-Enamel Felt-Base Floor Covering Fire Tests of Gunite Slabs and Partitions... Capacities of Plumbing Stacks in Buildings Live Loads on Floors in Buildings. Fire Resistance of Concrete Floors Fire Tests of Steel Columns Encased With Gypsum Lath and Plaster. Properties of Cavity Walls.

Influence of the Wash From Bronze on the Weathering of Marble 108 .

,

